\title{
A microarray analysis of gnotobiotic mice indicating that microbial exposure during the neonatal period plays an essential role in immune system development
}

\author{
Masahiro Yamamoto ${ }^{1,2}$, Rui Yamaguchi ${ }^{3}$, Kaori Munakata', Kiyoe Takashima', Mitsue Nishiyama², Kyoji Hioki ${ }^{4}$, \\ Yasuyuki Ohnishi ${ }^{4}$, Masao Nagasaki ${ }^{3}$, Seiya Imoto ${ }^{3}$, Satoru Miyano ${ }^{3}$, Atsushi Ishige $^{1}$ and Kenji Watanabe ${ }^{1 *}$
}

\begin{abstract}
Background: Epidemiological studies have suggested that the encounter with commensal microorganisms during the neonatal period is essential for normal development of the host immune system. Basic research involving gnotobiotic mice has demonstrated that colonization at the age of 5 weeks is too late to reconstitute normal immune function. In this study, we examined the transcriptome profiles of the large intestine (LI), small intestine (SI), liver (LIV), and spleen (SPL) of 3 bacterial colonization models-specific pathogen-free mice (SPF), ex-germ-free mice with bacterial reconstitution at the time of delivery (OWexGF), and ex-germ-free mice with bacterial reconstitution at 5 weeks of age (5WexGF) — and compared them with those of germ-free (GF) mice.

Results: Hundreds of genes were affected in all tissues in each of the colonized models; however, a gene set enrichment analysis method, MetaGene Profiler (MGP), demonstrated that the specific changes of Gene Ontology (GO) categories occurred predominantly in OWexGF LI, SPF SI, and 5WexGF SPL, respectively. MGP analysis on signal pathways revealed prominent changes in toll-like receptor (TLR)- and type 1 interferon (IFN)-signaling in LI of OWexGF and SPF mice, but not 5WexGF mice, while 5WexGF mice showed specific changes in chemokine signaling. RT-PCR analysis of TLR-related genes showed that the expression of interferon regulatory factor 3 (Irf3), a crucial rate-limiting transcription factor in the induction of type 1 IFN, prominently decreased in OWexGF and SPF mice but not in 5WexGF and GF mice.

Conclusion: The present study provides important new information regarding the molecular mechanisms of the so-called "hygiene hypothesis".
\end{abstract}

Keywords: Hygiene hypothesis, Germ-free, Toll-like receptor, Type 1 interferon, MetaGene Profiler

\section{Background}

The so-called "hygiene hypothesis" suggests that reduced exposure of children to microbes is associated with increased prevalence of common allergies in developed countries [1-3]. At birth, the gastrointestinal tract is sterile and the neonatal immune response is characterized

\footnotetext{
* Correspondence: watanabekenji@a6.keio.jp

${ }^{1}$ Center for Kampo Medicine, Keio University School of Medicine, 35 Shinanomachi, Shinjuku-ku, Tokyo 160-8582, Japan

Full list of author information is available at the end of the article
}

by a polarized $\mathrm{T}$ helper 2 (Th2) cytokine profile $[4,5]$. During gut colonization by commensal microorganisms, the gut immune system is constantly challenged by a myriad of bacterial and food antigens. Gut colonization apparently plays a major role in driving the initial Th2skewed immune response toward a more finely balanced Th1/Th2 response, by boosting counterregulatory Th1 immune responses [6]. Numerous studies using animal models have suggested the possible involvement of immunoregulatory lymphocytes, e.g., regulatory $\mathrm{T}$ cells (Treg) and/or interleukin-10 (IL-10) producing B cells and cytokines (IL-10 and transforming growth factor- $\beta$ ) 
in intestinal homeostasis, which are driven by the intestinal bacterial burden [7-9]

Many epidemiological studies suggest that there is an inverse relationship between infections in early childhood and the subsequent development of allergic diseases $[10,11]$. Therapy with broad-spectrum antibiotics is frequently performed in pediatric practice and children receiving this therapy within their first year of life are particularly prone to develop allergic diseases later in life [12-14]. Studies in animal models, such as GF animals, have also suggested that microbiota play a critical role in normal development of the immune system [15]. Oyama et al. [16] reported that antibiotic use during infancy in mice promotes a shift in the Th1/Th2 balance toward Th2-dominant immunity. Further, they demonstrated that GF mice do not develop oral tolerance, which was restored by microbial reconstitution in neonatal (3-week-old) mice but not in older mice [17]. Impairment of immune tolerance has been shown to augment disease in various models of allergy and/or autoimmunity, including diabetes onset in NOD mice $[18,19]$, collagen-induced arthritis $[20,21]$, and experimental colitis [22]. Taken together, these findings provide new perspectives on the pathogenesis and recurrence of these diseases [15,23,24]

In the present study, to elucidate the impact of microbes on the immune system during the neonatal period, we performed microarray analysis of LI, SI, LIV, and SPL of mice with or without enteric microbiota, and of GF mice reconstituted with microbiota at different ages.

In order to extract useful information from the massive amount of gene expression data obtained by microarray assay, we employed a gene set enrichment analysis approach in the present study. This type of analysis uses predetermined aggregations of genes (alternatively called gene sets, metagenes, gene modules, etc.) rather than individual genes to assess for coordinated expression in the samples. Single gene analysis may miss important effects on signaling because cellular processes often affect sets of genes acting in concert, with moderate effects on the strength of expression. Subtle but orchestrated changes of internally-related genes have often been found to be more important than a dramatic increase/decrease of a single gene. Therefore, it may be important to evaluate the statistical significance of changes in a gene aggregate or gene set, rather than in an individual gene. Since Subramanian et al.. [25] initially proposed "Gene Set Enrichment Analysis (GSEA)", a number of algorithms optimized for this type of analysis have been developed [26-33], and in the present study, we employed "MetaGene Profiler (MGP)" developed by Gupta et al. [34]. Unlike most existing methods, the main characteristic of MGP is that it evaluates statistical data for a set of genes independently from data of other gene sets. Because of the advantage of the analysis, it is logical to compare the results of tests for the same set of genes observed under different conditions, such as case-control experiments with multiple cases and time-course experiments, because the statistical evidence is evaluated using the same standard. MGP was therefore suitable for the present study, which required multiple cross comparisons of the same samples [35]. This study is part of a research project using GF and SPF mice of the IQI strain, which has been established as an inbred strain from ICR mice at the Central Institute for Experimental Animals (Kawasaki, Japan). We previously reported some of the results of microarray analyses conducted for the project. These studies indicated that 1) activation of the IFN- $\alpha$ system in LI differs significantly between GF and SPF mice [36], and 2) there is a striking commonality in transcriptome profiles between GF LI and SI, while the profiles of SPF LI and SI share almost nothing in common [37]. The present study, despite the use of different cohorts of animals, different versions of GeneChip arrays, and completely different strategies and algorithms for bioinformatics analysis from previous studies, has given support to our earlier findings. Furthermore, we demonstrated that the lack of neonatal encounter with commensal microorganisms may result in profound alteration of certain signaling pathways including TLRs, Rac 1, and type- 1 IFN, which cannot be restored by later exposure to microbiota. These findings may provide important insights into the molecular events underlying the interaction between neonatal immune systems and commensal microbiota.

\section{Results}

\section{Generation of gnotobiotic mice and targets of microarray} analysis

In the present study we prepared 4 groups of mice with different status of enteric flora: GF, SPF, 0WexGF, and 5WexGF (Figure 1). Bacterial reconstitution was executed not by oral administration of fecal suspension but by cohabitation of pregnant GF mice with female SPF mice of the same age, because 1) contact with microorganisms via a wide variety of parenteral routes such as birth canal, skin, eyes, ears, nostrils, airway, urinary tract, and vagina are also critically important for the establishment of relevant microbial flora, which differ profoundly among these anatomical sites, and 2) it is impossible to administer bacterial suspension orally to neonatal mice immediately after delivery.

Using GF and SPF mice of the same strain, we have analyzed the gene expression profiles of LI and SI in previous studies [36,37]. In the present study, we have extended the target of transcriptome analyses to the SPL 


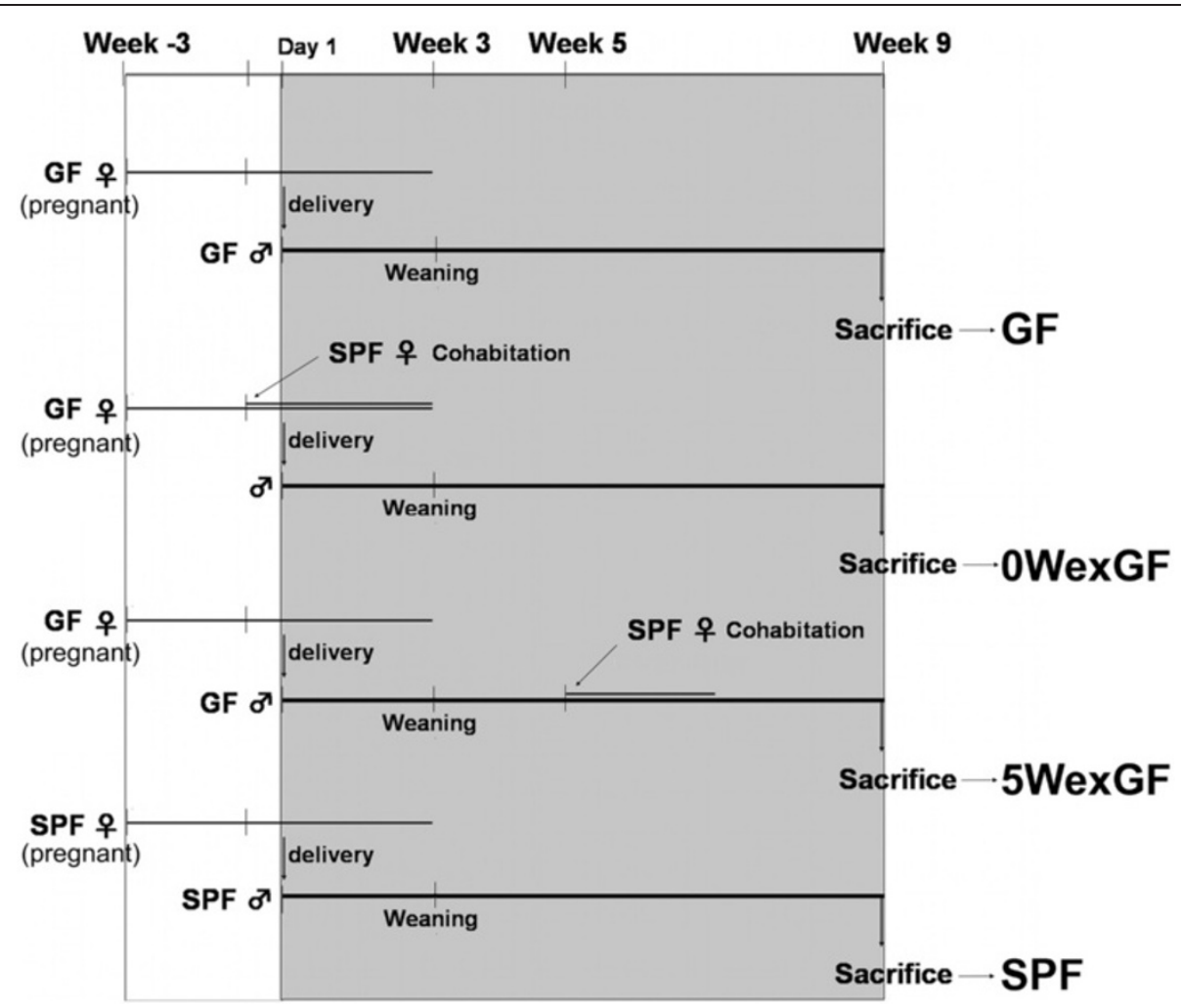

Figure 1 Overview of the experimental procedure for bacterial reconstitution. During the experiment, all mice (including SPF mice) were housed in a Trexler-type flexible film isolator in a standard germ-free state. For generation of OWexGF (mice, i.e., GF mice with bacterial reconstitution at the time of delivery), pregnant GF mice were housed with SPF female mice 1 day before delivery and only male pups were retrieved after weaning. To generate 5 WexGF mice (i.e., GF mice with bacterial reconstitution at 5 weeks old), since 5 weeks, GF male mice began to cohabit with SPF female mice of the same age. Male mice in all groups were sacrificed at 9 weeks of age.

and LIV in addition to the intestines. SPL is a key part of body's immune system and, therefore, comparison of the gene expression profiles of SPL and intestines may help to elucidate the cross-talk between intestinal local immunity and general immunity. The gene expression profile of LIV enzymes, especially those of steroid and xenobiotic metabolism, has been shown to be profoundly affected by intestinal microflora via nutrients and metabolites transported through portal vein [38]. Further, translocation of bacteria-derived substances, e.g., lipopolysaccharide to the LIV, is also known to have a great impact on the host immune system.

\section{GO analysis: overview and gene clustering}

Firstly, we have summarized the biological impact of enteric microbiota on host organs by MGP analysis on GO (http://www.geneontology.org/) categories. Figure 2 shows Venn diagrams of the numbers of differentially expressed genes and overrepresented GO categories of Biological Process (BP). Results from 3 comparisons (SPF vs. GF, 0 WexGF vs. GF, and 5 WexGF vs. GF) revealed alteration of an extremely large number of genes (probe sets) in the SI of SPF mice compared with those of OWexGF and
5WexGF mice. There were approximately 22 to 36 commonly regulated probe sets in the LI, SI, LIV, and SPL among the 3 colonization models. At least 300 probe sets were listed in each group in the LI, SI, and SPL; however, no or only a small number of GO categories were overrepresented in most cases with the exception of LI in 0WexGF mice, SI in SPF mice, and SPL in 5WexGF mice. The overrepresented GO categories are listed in Table 1 (LI of OWexGF), Table 2 (SI of SPF) and Table 3 (SPL of $5 \mathrm{WexGF).} \mathrm{Specific} \mathrm{alteration} \mathrm{of} \mathrm{genes} \mathrm{for} \mathrm{antigen} \mathrm{presen-}$ tation in LI of 0exGF mice, and for energy cycle and nervous development in SI of SPF mice, were identified from these tables.

The results of unsupervised hierarchical cluster analysis of gene expression patterns are shown in Figure 3, Figure 4, Figure 5 and Figure 6. The clusters denoting overrepresented GO categories included immune system development/B cell activation/hematopoiesis (in LI) and metabolic process/lipid metabolic process (in SI).

\section{Analysis of signal pathway}

Next, in order to gain information regarding the molecular events evoked by enteric microbiota, we applied 


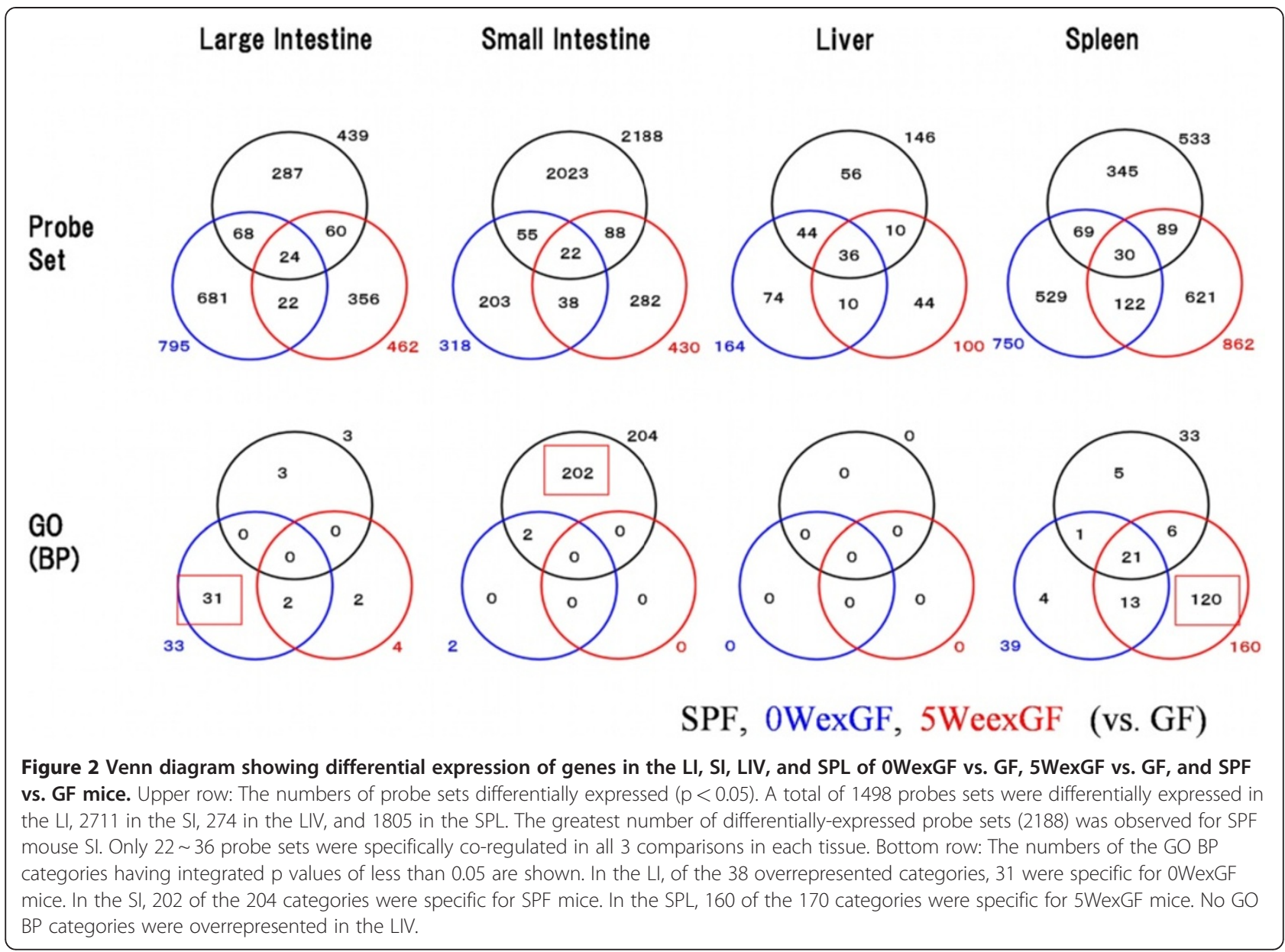

the gene set enrichment analysis program MGP to the signal pathway database of TRANTHPATH. Figure 7, Figure 8, and Figure 9 show the signal pathways overrepresented in LI, SI and SPL. TLR, Rac1, and IFN- $\alpha$ signaling were commonly overrepresented in the LI of SPF and OWexGF mice (note that "dsRNA/TLR3" pathways are closely interconnected with the pathways for IFN- $\alpha$ production) and epidermal growth factor (EGF) and nerve growth factor (NGF) signaling were common in the LI of 0WexGF and 5WexGF mice. There was low commonality between 5WexGF and SPF. In 5WexGF mice, specific alteration of gene expression for chemotaxis was indicated. The lists for SI differed from those of LI in SPF and OWexGF mice (Figure 8). However, surprisingly, the list for SI seemed essentially the same as that of LI in 5WexGF mice (Figure 7 and Figure 8). In all 3 groups, the profiles of SI were characterized by large scale alteration of EGF, platelet-derived growth factor (PDGF) and NGF/neurotrophin signaling. Overrepresentation of TLR pathway and Rac1 signaling was observed in 0WexGF SI but not in SPF SI. In SPL, only a few overrepresented signal pathways passed the statistical criteria $(q<0.001)$, but overrepresentation of TLR pathway and Rac1 signaling in 0WexGF mice and apoptosis pathway signaling in 5WexGF mice was noted. No pathways reached statistical significance of $\mathrm{q}<0.001$ in LIV.

\section{Investigation of TLR signaling by quantitative RT-PCR}

Gene set enrichment analysis provides useful information about the statistical significance of changes in the expression of gene sets. However, the analysis does not provide information on the degree and direction of change of expression for any particular gene. Furthermore, it is unlikely that any existing database would include all of the signaling pathways involved in complex physiological and pathophysiological events. For examples, "TLR pathway" in the TRANTPATH database seemed to contain relatively little information on TLR7 and TLR9. Therefore, in order to obtain more information regarding differences in TLR signaling, we investigated the expression of various TLR-related genes by real time RT-PCR analysis in LI of the 4 groups of mice. The results are summarized in Figure 10 in terms of the difference of gene expression compared with SPF mice. The status of enteric microbiota (absence, presence, and 
Table 1 Top 25 GO categories overrepresented in LI of OWexGF mice compared with GF mice

\begin{tabular}{|c|c|c|c|}
\hline GOID & Term & Number of Probes & p_int \\
\hline GO:0042254 & ribosome biogenesis and assembly & 92 & $<1.0 \mathrm{E}-18$ \\
\hline GO:0019886 & antigen processing and presentation of exogenous peptide antigen via MHC class II & 14 & $6.18 \mathrm{E}-08$ \\
\hline GO:0048511 & rhythmic process & 19 & $1.16 \mathrm{E}-07$ \\
\hline GO:0006954 & inflammatory response & 48 & $6.79 \mathrm{E}-07$ \\
\hline GO:0030300 & regulation of cholesterol absorption & 5 & 1.09E-06 \\
\hline GO:0006610 & ribosomal protein import into nucleus & 10 & $1.61 \mathrm{E}-06$ \\
\hline GO:0042157 & lipoprotein metabolic process & 8 & $2.00 \mathrm{E}-06$ \\
\hline GO:0001558 & regulation of cell growth & 64 & 2.63E-06 \\
\hline GO:0007166 & cell surface receptor linked signal transduction & 50 & $2.68 \mathrm{E}-06$ \\
\hline GO:0050766 & positive regulation of phagocytosis & 10 & $3.64 \mathrm{E}-06$ \\
\hline GO:0060048 & cardiac muscle contraction & 11 & 5.07E-06 \\
\hline GO:0007417 & central nervous system development & 17 & $6.65 E-06$ \\
\hline GO:0007413 & axonal fasciculation & 8 & $1.32 \mathrm{E}-05$ \\
\hline GO:0006911 & phagocytosis, engulfment & 7 & $1.52 \mathrm{E}-05$ \\
\hline GO:0006310 & DNA recombination & 27 & $1.54 \mathrm{E}-05$ \\
\hline GO:0002504 & antigen processing and presentation of peptide or polysaccharide antigen via MHC class II & 6 & $2.46 \mathrm{E}-05$ \\
\hline GO:0006950 & response to stress & 30 & 2.84E-05 \\
\hline GO:0000165 & MAPKKK cascade & 21 & $3.24 \mathrm{E}-05$ \\
\hline GO:0007585 & respiratory gaseous exchange & 12 & $3.92 \mathrm{E}-05$ \\
\hline GO:0006816 & calcium ion transport & 44 & 4.33E-05 \\
\hline GO:0042593 & glucose homeostasis & 18 & $5.19 \mathrm{E}-05$ \\
\hline GO:0006414 & translational elongation & 14 & 5.69E-05 \\
\hline GO:0030901 & midbrain development & 8 & $6.54 \mathrm{E}-05$ \\
\hline GO:0045582 & positive regulation of $\mathrm{T}$ cell differentiation & 6 & 7.88E-05 \\
\hline GO:0007229 & integrin-mediated signaling pathway & 36 & $8.14 \mathrm{E}-05$ \\
\hline
\end{tabular}

MGP analysis was performed on GO BP categories which contains 4 99 genes ("Number of Probes"). The categories were sorted according to the integrated $p$ value (p_int) and the top 25 are represented. The categories related to antigen presentation are noted (e.g., "antigen processing and presentation of exogenous peptide antigen via MHC class II", "inflammatory response", "positive regulation of phagocytosis", "phagocytosis, engulfment", "antigen processing and presentation of peptide or polysaccharide antigen via MHC class II" and "positive regulation of T cell differentiation").

introduction at different times) influenced various TLRrelated genes in diverse ways. The most prominent and specific changes were seen in TLR7/9 (enteric microbiota, irrespective of colonization protocols, strongly decreased TLR7/9 expression) and IRF3 (expression was very low in SPF and OWexGF mice and high in GF and 5WexGF mice).

\section{Discussion}

In our previous study [36], using GF and SPF IQI mice and the old version of Affimetrix GeneChip (MGU74Av2), we compared gene expression profiles of LI in GF and SPF mice. A list of genes most affected by the presence of enteric microbiota was generated by the simple Welch's t-statistic and enumeration in the order corresponding to the fold-change. The list clearly indicated that the expression of genes related to the induction and production of type 1 IFN, such as Irf3, Irf7, Isgf3g, Ifit1 and G1p2 (ISG15), was markedly decreased in SPF mice compared with GF mice. In situ hybridization and immunohistochemistry indicated that these IFN-related genes were expressed mainly in lamina proprial $\mathrm{CD}_{11 \mathrm{~b}^{+}}$cells. In another study [37], using a synthetic IFN inducer and an herbal medicine that enhances IFN production, we demonstrated that the difference in the steady-state expression level of these IFNrelated genes was correlated with the difference in the timing of IFN- $\alpha$ release triggered by the inducer. In the present study, we used the same mouse strain but a different version of GeneChip (Mouse Expression 430A) and employed a completely different strategy and algorithm for bioinformatic analysis. In place of single gene analysis, we have adopted a gene set enrichment analysis with the primary aim of identifying the most affected gene sets in terms of statistical significance. The predetermined gene sets of categories, cascades and pathways have been furnished from public (GO) and commercial (TRANTHPATH) databases. The results indicated that, 


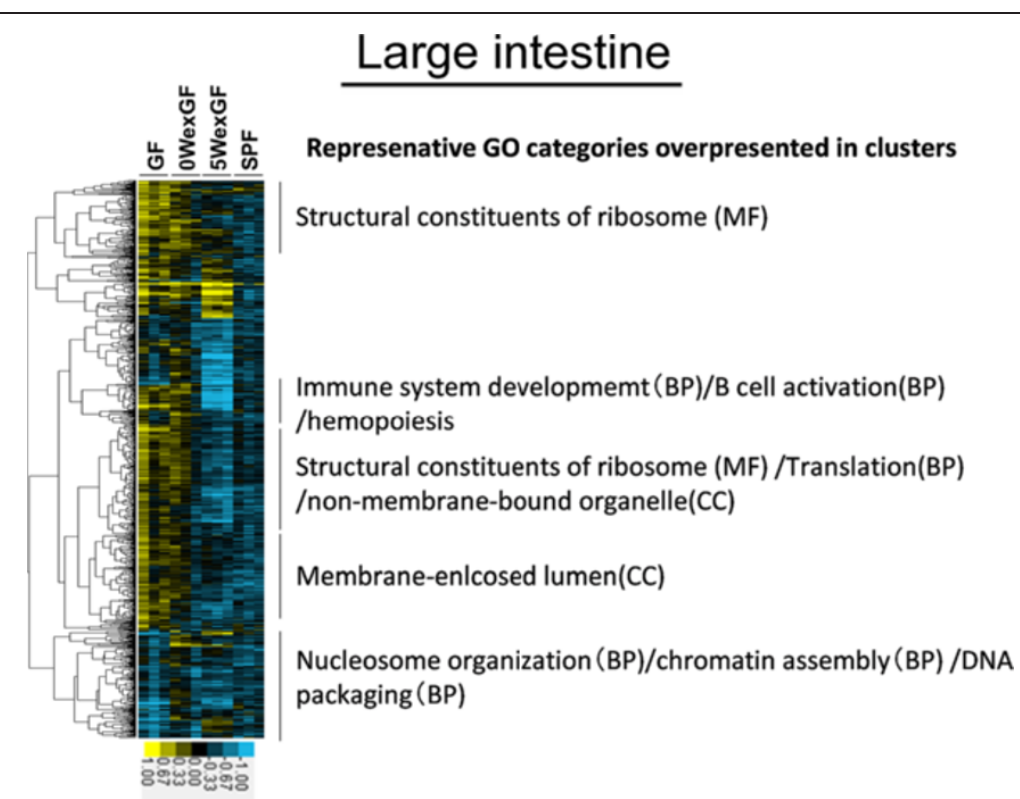

Figure 3 Hierarchical cluster analysis of the $\mathbf{1 4 9 8}$ differentially-expressed genes in the LI. Expression was increased or decreased at a significance level of $p<0.05$. Gene tree (Pearson correlation: left tree) shows correlated groups of genes and their expression patterns across all individual samples (top axis). The 5 groups highlight the separation of the gene clusters. MGP analysis was performed for each cluster and the top $1 \sim 3 \mathrm{GO}$ categories (BP, MF, or/and CC) were listed. Colors show the range of expression from blue (decreased expression) to yellow (increased expression).

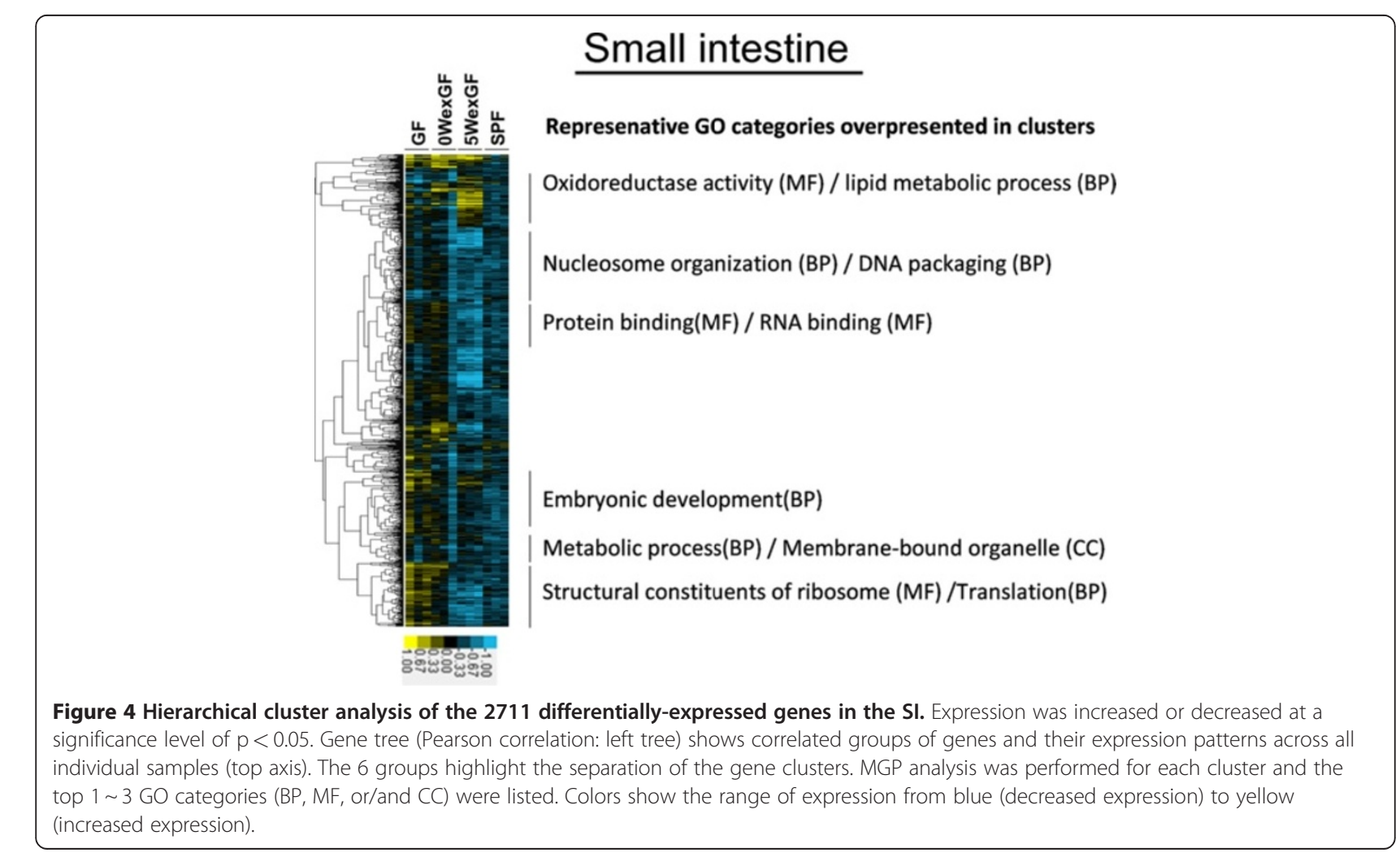




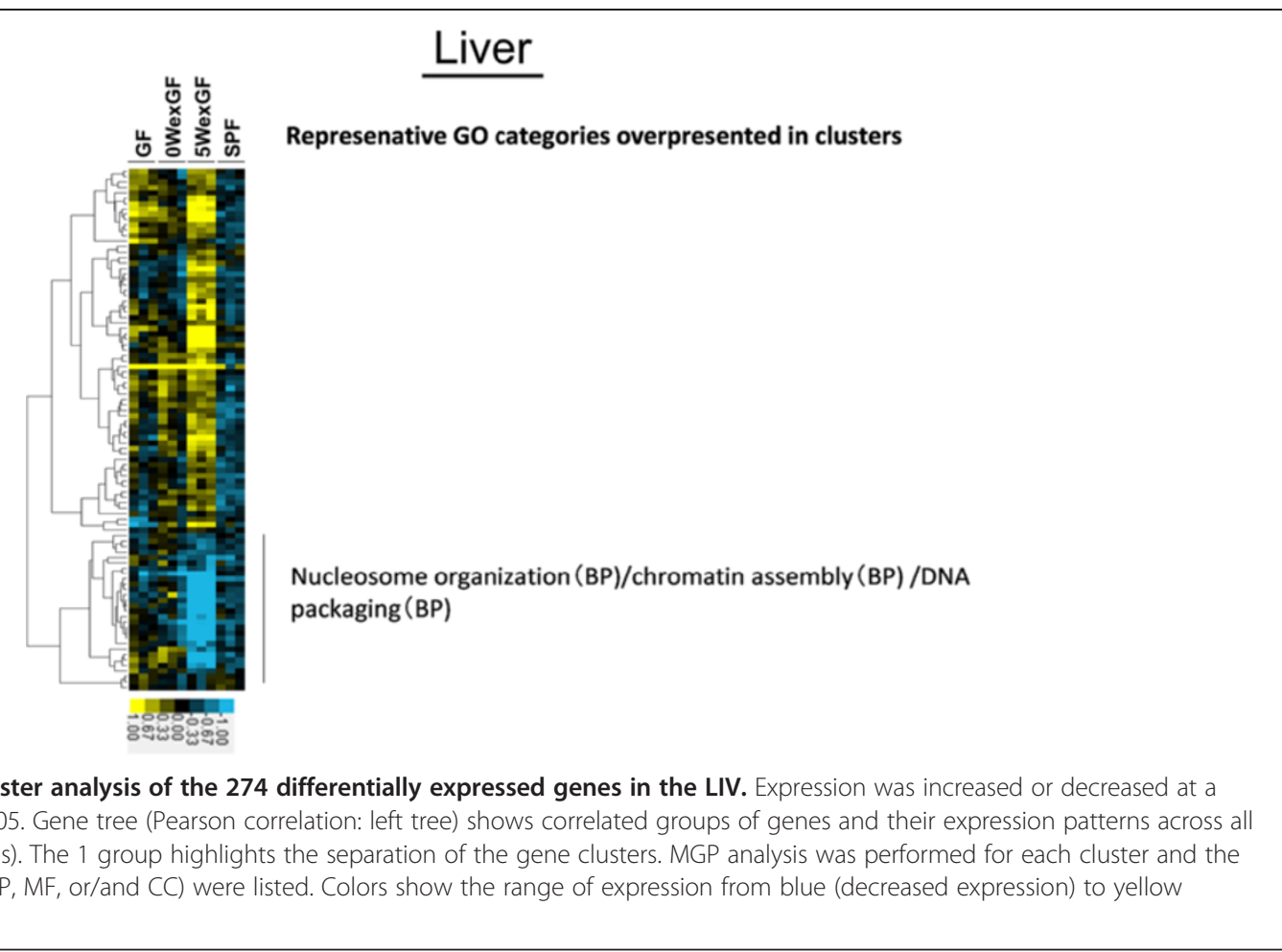

Figure 5 Hierarchical cluster analysis of the $\mathbf{2 7 4}$ differentially expressed genes in the LIV. Expression was increased or decreased at a significance level of $p<0.05$. Gene tree (Pearson correlation: left tree) shows correlated groups of genes and their expression patterns across all individual samples (top axis). The 1 group highlights the separation of the gene clusters. MGP analysis was performed for each cluster and the top $1 \sim 3 \mathrm{GO}$ categories (BP, MF, or/and CC) were listed. Colors show the range of expression from blue (decreased expression) to yellow (increased expression).

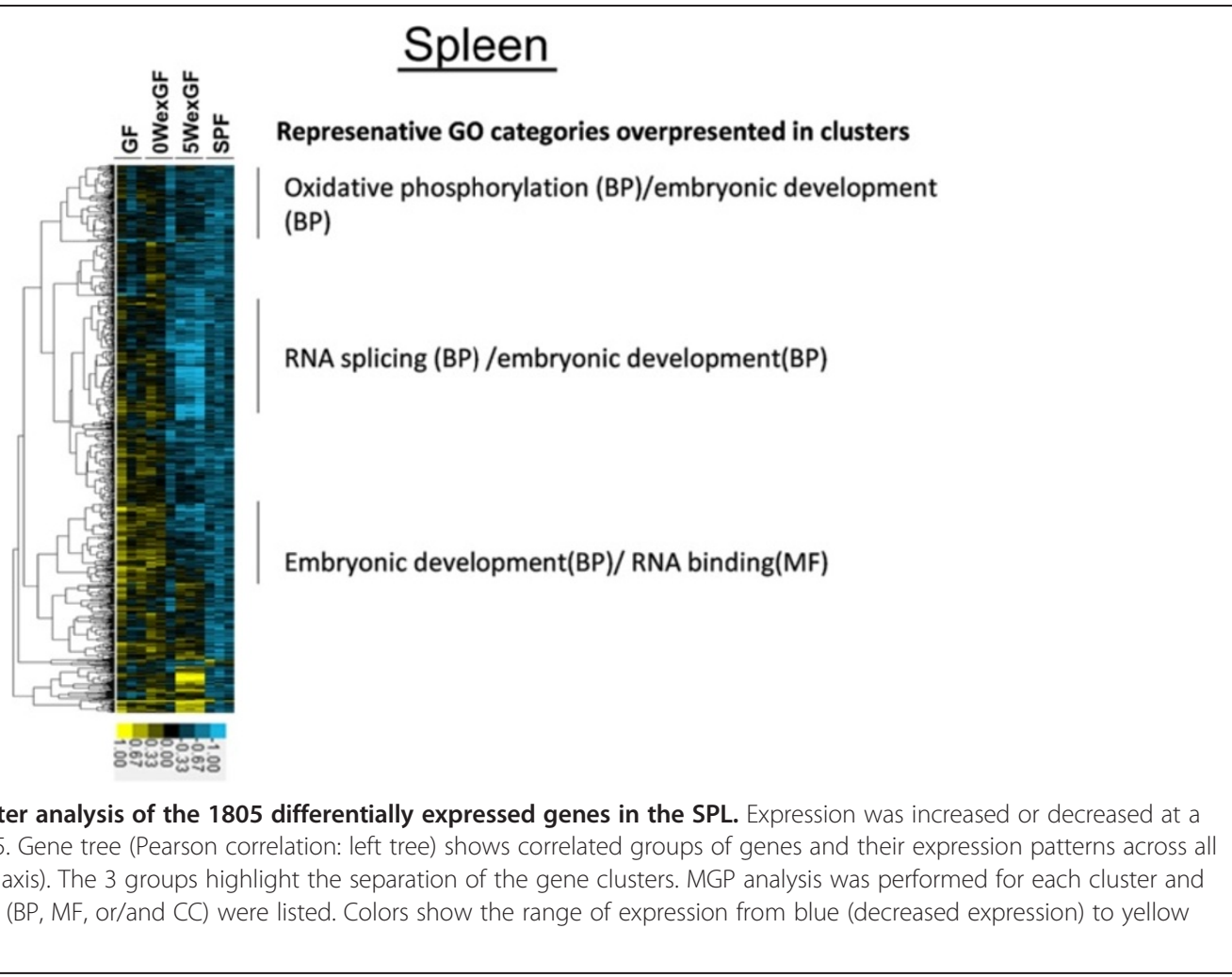




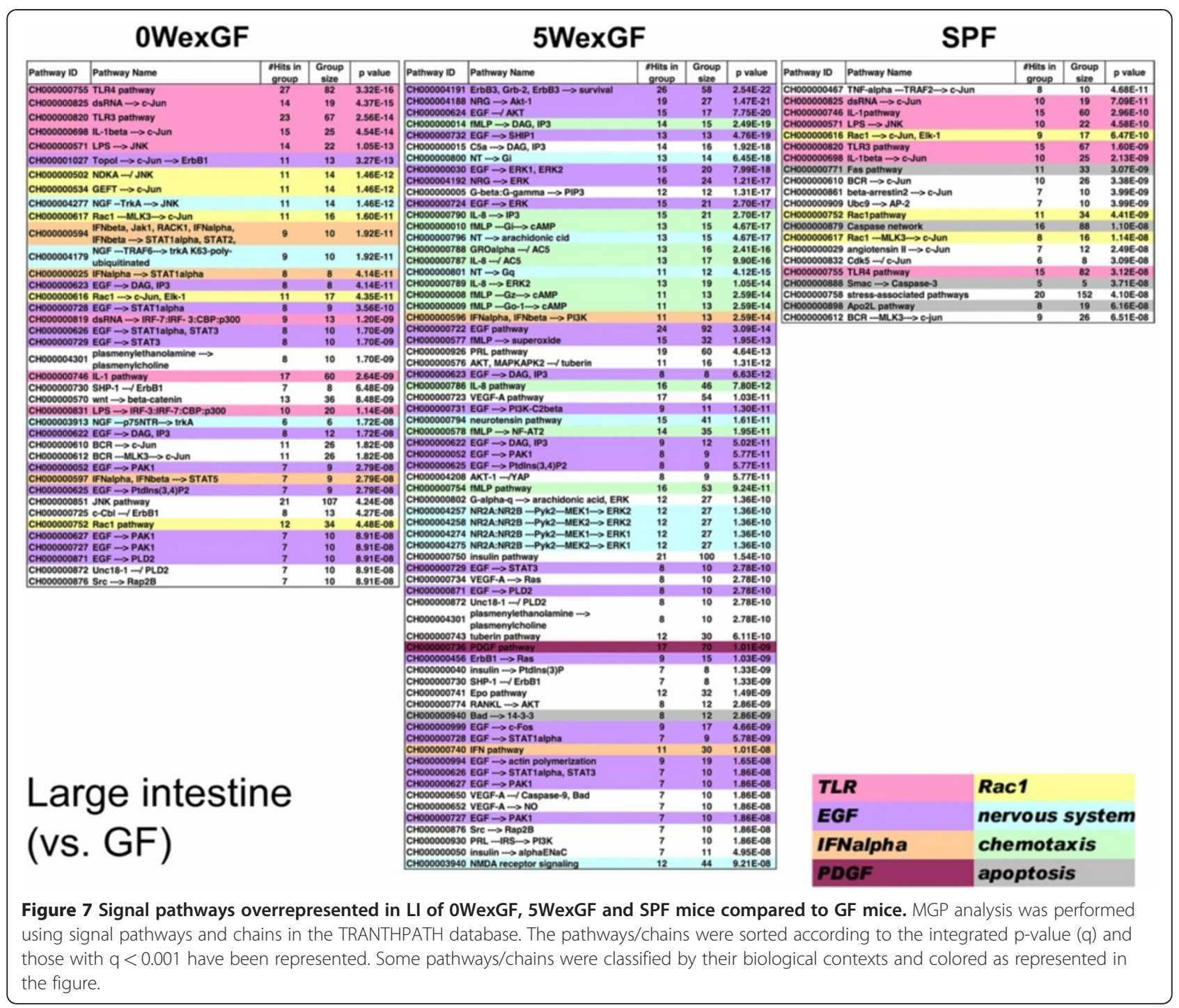

together with TLR signaling and Rac1 signaling, the signaling cascade for the production of type 1 IFN was most prominently affected in SPF and 0WexGF mice. Further, in good accordance with our previous paper [37], the changes in gene expression profiles were dissimilar between SI and LI of SPF mice, while those in GF mice showed substantial commonality between SI and LI.

The gene expression profile of SPF mice was similar to that of 0WexGF, particularly in LI, but not to that of 5WexGF mice. The main differences were observed in TLR, Rac1, and IFN- $\alpha$ signaling. TLRs play an important role in the recognition of microbes by host sentinel cells that contribute to subsequent innate and adaptive immune responses [39]. TLRs recognize molecular patterns specific for microbes to eliminate pathogens and engender commensal colonization of symbiotic bacteria [40].
Therefore, the difference in TLR signaling may contribute to the altered immune function of 5WexGF mice. Similarly, 5WexGF mice may have unique characteristics with respect to the IFN- $\alpha$ response, which is critically important not only for protection against infection by virus and certain microorganism, but also for control of autoimmune responses. Only in 5WexGF intestines, both SI and LI, large scale alteration of chemokine signaling was observed. In response to microbial stimuli, fetal intestinal epithelial cells release chemokines very rapidly, and this response may be a prerequisite for intestinal tolerance to commensal bacteria [41]. Acute chemokine release in response to microbial activation was subsequently maintained for several days in GF mice, but did not occur in mice harboring conventional microbiota due to tolerance acquisition at birth [42]. To clarify how the observed changes in the expression 


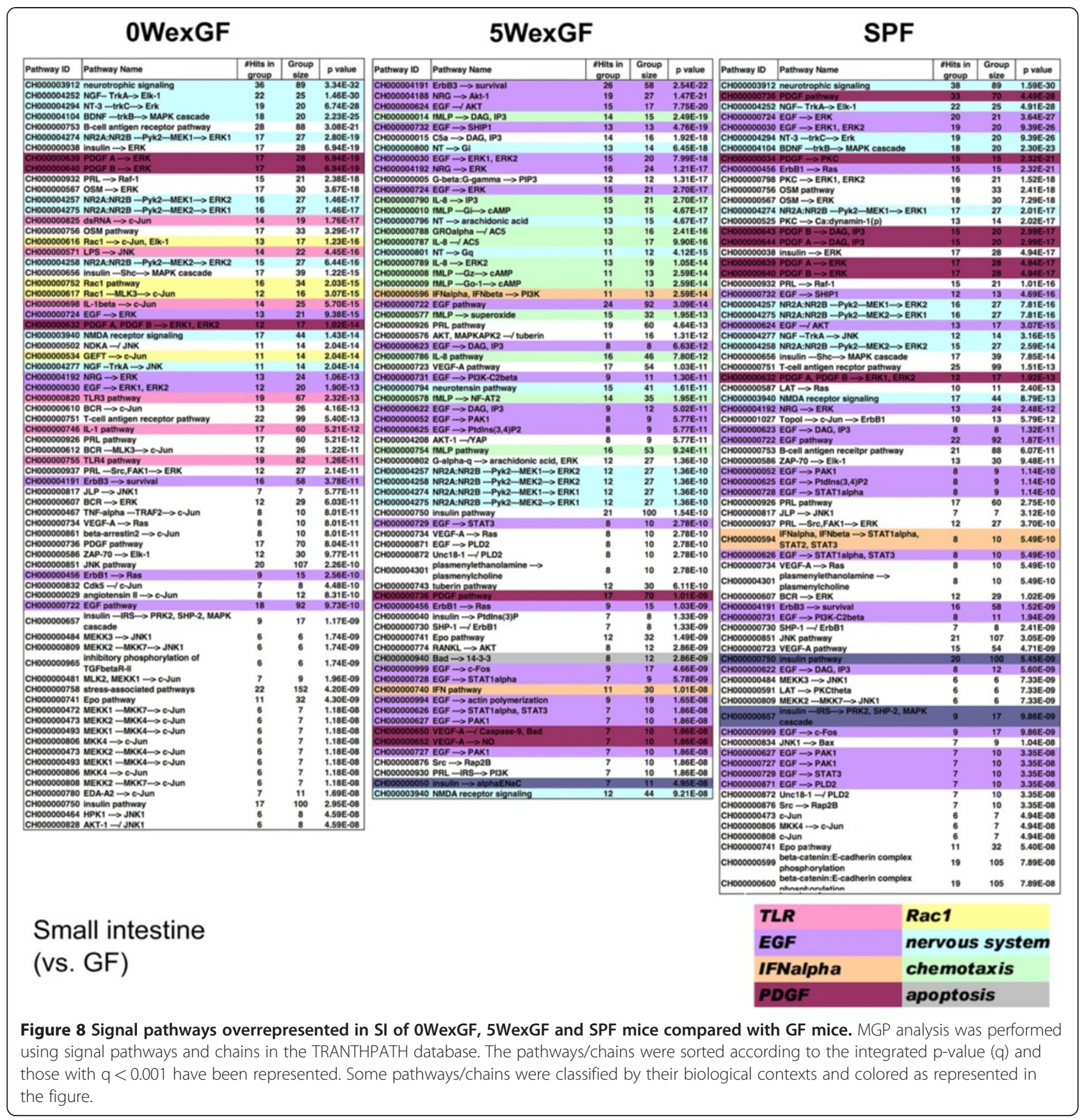

profile of chemokine signaling in 5WexGF mice relates to the failure to acquire immune tolerance, it may be necessary to examine chemokine production in epithelial cells isolated from 5WexGF intestines. Our findings collectively suggest that the encounter with environmental microbiota during the specific time interval within the neonatal period is critically important for the development of normal immune system responsiveness to microorganisms, both commensal and infectious.

Previous transcriptomics studies focusing on the role of commensal bacteria [43-46] differ from the present study with respect to animal species (mice vs. rats vs. piglets), tissues (epithelium/epithelial cells vs. whole intestines), ages at the time of sampling (pups vs. puberty vs. adult), means of manipulation of microbiota (conventionalization vs. monoassociation vs. antibiotic eradication of bacteria), microarray platforms, and statistical methodologies. However, the results of these studies are similar to ours in several respects such as prominent alteration of the expression profiles for antigen presentation, xenobiotic systems, and IFN signaling. To shed additional light on the "hygiene hypothesis", a careful 


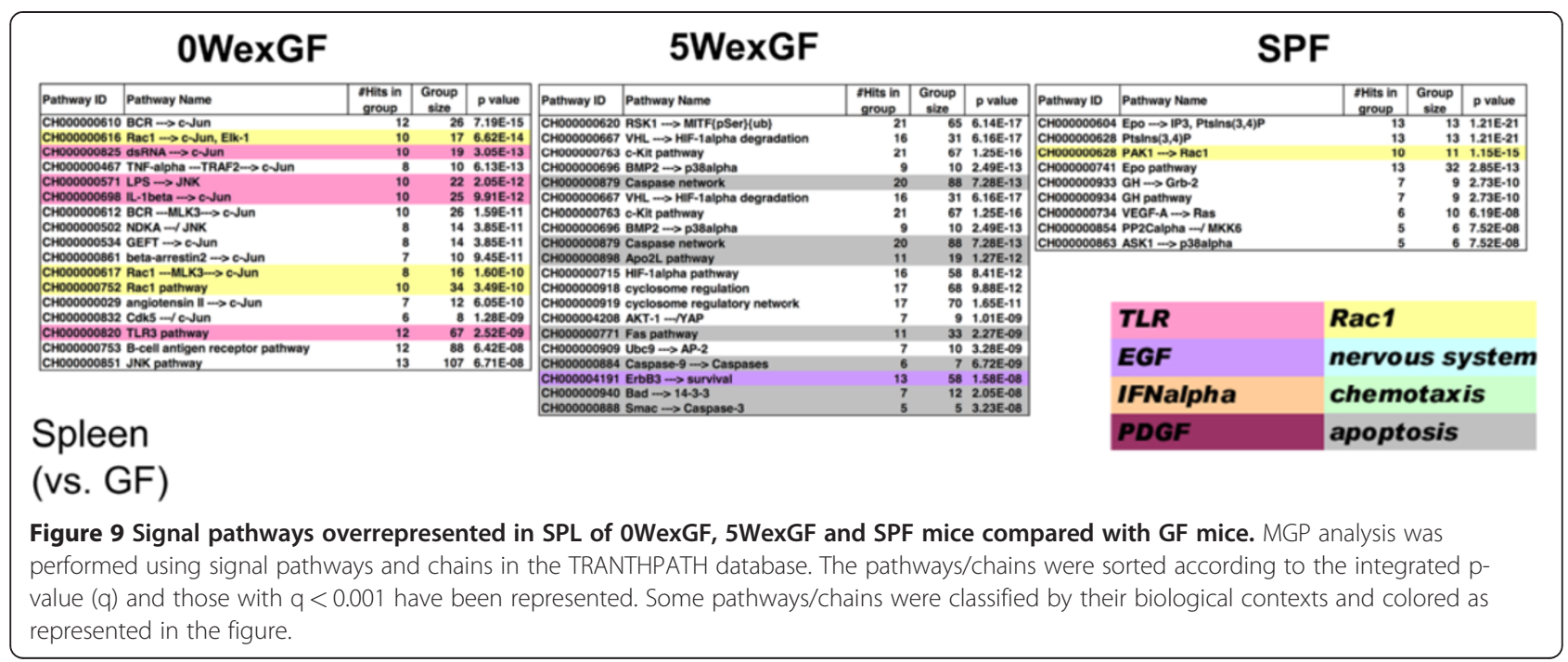

comparison of our results with those of Schumann et al. [43] would be particularly valuable because in the latter study, enteric bacteria were eradicated by antibiotic treatment of neonatal rats from postnatal day 7 to 21 . In the study by Schumann and colleagues, in addition to significant down-regulation of antigen presentation systems, expression of paneth cell products such as $\alpha$ defensins, matrylsin, and type IIA phospholipase A2 decreased and expression of mast cell proteases increased as a result of a drastic reduction in enteric bacteria evoked by antibiotics. Similar changes were observed in the SI of GF mice compared with the other 3 colonization models in the present study (data not shown). Furthermore, Schumann et al.. have also found that eradication of enteric bacteria had a greater effect, in terms of the number of affected probe sets, in SI than in the colon. Clustering analysis of the affected probe sets in the study revealed only a few functional categories; i.e., endocytosis and vesicle-mediated transport in the proximal SI, immune response in the distal SI, and ion transport processes in the colon. The present analysis based on MGP identified expression changes for many functional categories, including proton transport and vesicle-mediated transport in the SI (Table 2) and immune responses in the LI (Table 1). In spite of the extensive differences in species, experimental settings, microarray platforms, and approaches to statistical analysis, a detailed comparative examination of these two transcriptome data sets might provide new insights into the impact of commensal microbiota colonization during the neonatal period.

\section{Conclusions}

In summary, the gene expression profiles of mice with bacterial colonization at different times suggest that the encounter with environmental commensal microbiota during the specific time interval within neonatal period is essential for normal development of the immune system, especially of the LI. Microbiota-mediated development of regulatory circuits of TLRs and type I IFN seem to play a particularly important role. Rectification of chemokine expression might also be involved in microbiota-related immunological dysregulation because expression of chemokines was activated specifically in mice colonized at pre-pubertal ages. The present study provides important insights for clarification and refinement of the so-called "hygiene hypothesis".

\section{Methods}

\section{Animals}

All animal experiments were performed in Central Institute of Experimental Animals (CIEA; Kanagawa, Japan). IQI/Jic mice were kept under SPF and GF mice were housed in a Trexler-type flexible film isolator in a standard germ-free state and screened on a weekly basis for germ-free status by sterile feces sampling and culturing on MRS-agar plates under aerobic and anaerobic conditions. Mice were housed in an air-conditioned room (temperature $24 \pm 1{ }^{\circ} \mathrm{C}$ ) with a controlled light/dark cycle (light on between 6:30 AM and 7:00 PM). Sterile food and water were available ad libitum. The mice were randomly divided into 4 groups; 10 male mice were included in each group. GF, SPF, OWexGF, and 5WexGF mice (Figure 1). For generation of 0WexGF mice, pregnant GF mice were housed with SPF female mice 1 day before delivery and only male pups were retrieved after weaning. To generate 5WexGF mice, 5-week-old GF male mice were housed with SPF female mice. Mice in all groups were sacrificed at 9 weeks of age. All animal procedures were approved by the institution's ethical committee for care and use of laboratory animals in research. 


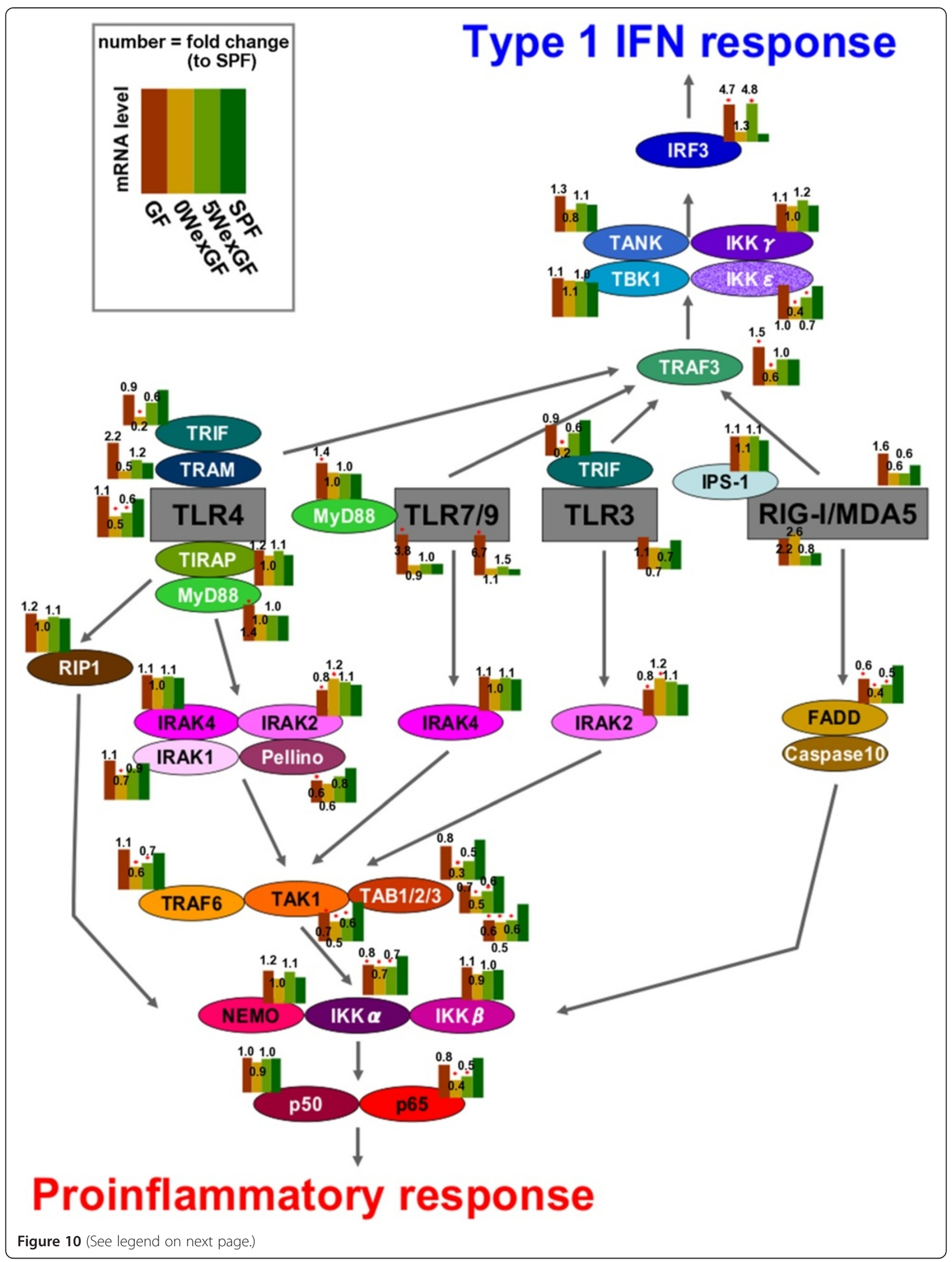


(See figure on previous page.)

Figure 10 Summary of the results of RT-PCR of TLR-related genes in LI. The molecules involved in TLR signaling are shown in two clusters: one leads to the induction of proinflammatory cytokines in an NFKB-dependent manner, and the other leads to the production of type 1 IFN in an NFkB-independent manner. Expression levels are represented by columns indicating the relative value of each group normalized to the maximum value in the four groups. Number represents fold-change to the expression level in SPF. Brown, GF; ocher, oWexGF; light green, 5WexGF; dark green, SPF. Differences compared with SPF mice were analyzed by Dunnet test. ${ }^{*} p<0.05$.

\section{RNA extraction from mouse tissue}

Mice were sacrificed and the LI, SI, LIV, and SPL were harvested for preparation of total RNA. Each frozen sample was homogenized in $1 \mathrm{ml} / 0.1 \mathrm{~g}$ tissue of TRI Reagent (Sigma-Aldrich Japan, Tokyo, Japan) with a Polytron tissue homogenizer (Kinematica, Littau-Lucerne, Switzerland) and incubated for 10 minutes at RT. Chloroform ( $0.2 \mathrm{ml} / 1 \mathrm{ml}$ TRI Reagent) was added to the samples and the suspensions were centrifuged at $13,200 \times g$ for $15 \mathrm{~min}$ at $4{ }^{\circ} \mathrm{C}$. The water phase was transferred to a new tube and the RNA was prepared using a conventional isopropanol/ethanol precipitate technique.

\section{Microarray analysis}

Total RNA extracted from mice ( $\mathrm{n}=3$ per each group) were re-purified using RNeasy spin columns (Qiagen, Valencia, CA) according to the manufacturer's instructions. All samples were monitored using an Agilent

Table 2 Top 25 GO categories overrepresented in SI of SPF mice compared to GF mice

\begin{tabular}{|c|c|c|c|}
\hline GOID & Term & Number of Probes & p_int \\
\hline GO:0015992 & proton transport & 67 & $<1.0 \mathrm{E}-18$ \\
\hline GO:0015986 & ATP synthesis coupled proton transport & 44 & $<1.0 \mathrm{E}-18$ \\
\hline GO:0006099 & tricarboxylic acid cycle & 39 & $<1.0 \mathrm{E}-18$ \\
\hline GO:0016192 & vesicle-mediated transport & 95 & $<1.0 \mathrm{E}-18$ \\
\hline GO:0006631 & fatty acid metabolic process & 63 & $<1.0 \mathrm{E}-18$ \\
\hline GO:0045454 & cell redox homeostasis & 46 & $1.11 \mathrm{E}-16$ \\
\hline GO:0006754 & ATP biosynthetic process & 40 & $2.78 \mathrm{E}-15$ \\
\hline GO:0006096 & Glycolysis & 56 & $5.32 \mathrm{E}-13$ \\
\hline GO:0016481 & negative regulation of transcription & 68 & $1.05 \mathrm{E}-12$ \\
\hline GO:0042254 & ribosome biogenesis and assembly & 96 & $2.27 \mathrm{E}-11$ \\
\hline GO:0009987 & cellular process & 85 & $2.41 \mathrm{E}-11$ \\
\hline GO:0001501 & skeletal development & 27 & 3.77E-11 \\
\hline GO:0006461 & protein complex assembly & 52 & 3.84E-11 \\
\hline GO:0021799 & cerebral cortex radially oriented migration & 5 & $5.23 \mathrm{E}-11$ \\
\hline GO:0021813 & $\begin{array}{l}\text { cell-cell adhesion involved in neuronal-glial interactions } \\
\text { involved in cerebral cortex glial-mediated radial cell migration }\end{array}$ & 5 & $5.23 \mathrm{E}-11$ \\
\hline GO:0021589 & cerebellum structural organization & 5 & $5.23 \mathrm{E}-11$ \\
\hline GO:0021942 & radial glia guided migration of Purkinje cell & 5 & $5.23 \mathrm{E}-11$ \\
\hline GO:0000160 & two-component signal transduction system (phosphorelay) & 31 & $6.78 \mathrm{E}-11$ \\
\hline GO:0008654 & phospholipid biosynthetic process & 41 & $1.00 \mathrm{E}-10$ \\
\hline GO:0007031 & peroxisome organization and biogenesis & 20 & 4.44E-10 \\
\hline GO:0007399 & nervous system development & 96 & $7.76 \mathrm{E}-10$ \\
\hline GO:0044267 & cellular protein metabolic process & 26 & $1.06 \mathrm{E}-09$ \\
\hline GO:0006396 & RNA processing & 75 & 1.15E-09 \\
\hline GO:0007162 & negative regulation of cell adhesion & 11 & 2.04E-09 \\
\hline GO:0007266 & Rho protein signal transduction & 38 & 2.27E-09 \\
\hline GO:0007229 & integrin-mediated signaling pathway & 36 & $8.14 \mathrm{E}-05$ \\
\hline
\end{tabular}

MGP analysis was performed on GO BP categories which contains 4 99 genes ("Number of Probes"). The categories were sorted according to the integrated p value (p_int) and top 25 are represented. The categories related to energy cycle are noted (e.g., "proton transport", "tricarboxylic acid cycle", "ATP biosynthetic process", and "Glycolysis"). 
Table 3 Top 25 GO categories overrepresented in SPL of 5WexGF mice compared with GF mice

\begin{tabular}{|c|c|c|c|}
\hline GOID & Term & Number of Probes & p_int \\
\hline GO:0007507 & heart development & 91 & $1.98 \mathrm{E}-13$ \\
\hline GO:0006952 & defense response & 63 & 4.39E-12 \\
\hline GO:0016192 & vesicle-mediated transport & 76 & 3.47E-11 \\
\hline GO:0015992 & proton transport & 64 & 1.69E-09 \\
\hline GO:0001764 & neuron migration & 32 & 2.46E-09 \\
\hline GO:0007283 & Spermatogenesis & 94 & 2.65E-09 \\
\hline GO:0006816 & calcium ion transport & 41 & $3.52 \mathrm{E}-09$ \\
\hline GO:0030036 & actin cytoskeleton organization and biogenesis & 52 & $3.81 \mathrm{E}-09$ \\
\hline GO:0042127 & regulation of cell proliferation & 46 & 8.17E-09 \\
\hline GO:0016055 & Wnt receptor signaling pathway & 61 & $1.16 \mathrm{E}-08$ \\
\hline GO:0007010 & cytoskeleton organization and biogenesis & 43 & $1.52 \mathrm{E}-08$ \\
\hline GO:0016337 & cell-cell adhesion & 33 & $2.30 \mathrm{E}-08$ \\
\hline GO:0018108 & peptidyl-tyrosine phosphorylation & 25 & $2.51 \mathrm{E}-08$ \\
\hline GO:0008610 & lipid biosynthetic process & 76 & 2.69E-08 \\
\hline GO:0009987 & cellular process & 78 & $3.52 \mathrm{E}-08$ \\
\hline GO:0006954 & inflammatory response & 48 & 4.44E-08 \\
\hline GO:0006874 & cellular calcium ion homeostasis & 23 & $6.93 \mathrm{E}-08$ \\
\hline GO:0007166 & cell surface receptor linked signal transduction & 54 & 9.30E-08 \\
\hline GO:0005975 & carbohydrate metabolic process & 81 & $1.01 \mathrm{E}-07$ \\
\hline GO:0016311 & Dephosphorylation & 61 & $1.76 \mathrm{E}-07$ \\
\hline GO:0042981 & regulation of apoptosis & 83 & 2.21E-07 \\
\hline GO:0007420 & brain development & 30 & 3.64E-07 \\
\hline GO:0006935 & Chemotaxis & 45 & 4.40E-07 \\
\hline GO:0001701 & in utero embryonic development & 55 & 5.95E-07 \\
\hline GO:0009408 & response to heat & 26 & $8.93 \mathrm{E}-07$ \\
\hline
\end{tabular}

MGP analysis was performed on GO BP categories which contains $4 \sim 99$ genes ("Number of Probes"). The categories were sorted according to the integrated $p$ value (p_int) and top 25 are represented.

Bioanalyzer (Agilent Biotechnologies, Boeblingen, Germany) and consistently demonstrated high-quality RNA (28 S/18 S ratio, $\sim 2$ ). The labeled cRNA prepared from 200 ng total RNA by in vitro transcription (Enzo Biochem, New York, NY) was fragmented, hybridized to a Mouse Expression 430 array (Affymetrix, Santa Clara, CA) using an Affymetrix fluidics station, and scanned with an Affymetrix scanner, according to the Affymetrix protocol. Data were uploaded to the Center for Information Biology Gene Expression Database (CIBEX, http://cibex.nig.ac.jp/index.jsp) and are available under accession ID CBX256. Data were analyzed using the Affymetrix Microarray Suite [37] v.5.0 with all of the parameters set at default values (a global normalization was applied). Probe sets that had 2 or 3 absent A MAS detection calls per group (3 samples) in all groups were excluded. Therefore, genes that had more than 2 present calls in any one of the groups were included in the analysis. Probe annotations were obtained from the
Affymetrix NetAffx Analysis Center. Functional and signal pathway annotation of transcripts was based on Gene Ontology [47] and TRANSPATH [48] term assignments, respectively.

\section{Data clustering}

Hierarchical clustering of subsets of genes was performed using clustering and analysis software (Cluster 3.0; http://bonsai.hgc.jp/ mdehoon/software/ cluster/software.htm). The Pearson correlation coefficient ( $r$ ) was chosen to compute distances between expression vectors $(d=1-r)$, and the complete linkage clustering algorithm was used to build the hierarchical tree.

\section{MetaGene Profiler (MGP)}

MGP has been developed to evaluate the significance of predefined sets of genes from transcriptome data (http:// metagp.ism.ac.jp/) [34]. The method, which employs a 
meta-analysis technique, accumulates statistical evidence from a set of genes in order to build a more powerful test than can be achieved by analyzing individual genes. In the present study, we first predefined the group of genes for each GO term: all 3 categories, i.e., BP, cellular component $(\mathrm{CC})$, and molecular function $(\mathrm{MF})$, were used. More than 20,000 gene sets were annotated by GO terms. We also used gene sets defined by pathways in the TRANSPATH database. To obtain the p-values for individual genes, Welch's $t$ test was performed. The individual $\mathrm{p}$-values of the genes included in the gene set were integrated to obtain the integrated $\mathrm{p}$-value for the gene set, as described previously (http://metagp.ism.ac. $\mathrm{jp} /$ ). A gene set containing too small a number of genes is, in principle, unsuitable for evaluation of overrepresented gene sets. Preliminary examination suggested that GO terms containing more than 100 genes provided relatively little information because these terms represent too broad a concept to give a foothold for further biological investigation. Therefore MGP analysis was applied to gene sets consisting of 4-99 genes.

\section{Quantitative real time RT-PCR}

For RT-PCR, total RNA was extracted as described above ( $\mathrm{n}=6$ per group). The cDNA samples were synthesized using an Improm-IITM Reverse Transcriptase kit (Promega Corporation, Madison, Wl) according to the manufacturer's instructions. Briefly, $5 \mu \mathrm{l}$ of RNA (50 ng) and primer were added to $15 \mu \mathrm{l}$ of reverse transcription reaction mix (Improm-IITM Reverse Transcriptase system). Annealing was performed by placing the tubes in a controlled-temperature heat block equilibrated at $25{ }^{\circ} \mathrm{C}$ and incubated for 5 minutes. Extension was performed in a controlled-temperature heat block at $42{ }^{\circ} \mathrm{C}$ for up to 1 hour. The extension temperature was optimized between $37{ }^{\circ} \mathrm{C}$ and $55^{\circ} \mathrm{C}$. Real time RT-PCR was performed using the TaqMan ${ }^{\circledR}$ Gold RT-PCR Kit (Applied Biosystems, Foster City, CA) according to the manufacturer's instructions. An ABI Prism 7900HT (Applied Biosystems) was used with the following thermal cycling conditions: 1 cycle at $50{ }^{\circ} \mathrm{C}$ for $2 \mathrm{~min}, 1$ cycle at $95{ }^{\circ} \mathrm{C}$ for $10 \mathrm{~min}, 40$ cycles each at $95^{\circ} \mathrm{C}$ for $15 \mathrm{sec}$ and $60{ }^{\circ} \mathrm{C}$ for $1 \mathrm{~min}$. Data were normalized against Irf1 $[36,37]$.

\section{Statistical analyses}

PCR data were calculated as the mean values and are represented in Figure 10 by columns indicating the relative value of each group, which was normalized to the maximum value in the 4 groups. Differences in mean values among groups were analyzed by Dunnet test and were considered significant at $\mathrm{p}<0.05$. The statistical methods used for the microarray analysis are described above.

\section{Abbreviations}

OWexGF: Germ-free mice with bacterial reconstitution at the time of delivery; 5WexGF: Germ-free mice with bacterial reconstitution at 5 weeks of age; BP: Biological Process; CC: Cellular Component; GF: Germ-free; GO: Gene Ontology; GSEA: Gene set enrichment analysis; IFN: Interferon; IL: Interleukin; LI: Large intestine; MF: Molecular Function; MGP: MetaGene Profiler; SI: Small intestine; SPF: Specific pathogen free; Th: T helper; TLR: Toll like receptor; Treg: Regulatory $\mathrm{T}$.

\section{Competing interests}

The authors declare that they have no competing interests.

\section{Acknowledgements}

This work was supported by Keio University School of Medicine, Central Institute for Experimental Animals and Tsumura Research Laboratories.

\section{Author details}

${ }^{1}$ Center for Kampo Medicine, Keio University School of Medicine, 35 Shinanomachi, Shinjuku-ku, Tokyo 160-8582, Japan. ${ }^{2}$ Tsumura Research Laboratories, Tsumura \& Co., Ami, Ibaraki 300-1192, Japan. ${ }^{3}$ Human Genome Center, Institute of Medical Science, University of Tokyo, Tokyo, 108-8639, Japan. ${ }^{4}$ Central Institute for Experimental Animals, Kawasaki, Kanagawa 216-0001, Japan.

\section{Authors' contributions}

MY participated in the design of the study, data analysis, coordination, and drafted the manuscript. RY carried out microarray data analysis including MGP. KM participated in animal experiments. MiN and KT carried out RT-PCR. $\mathrm{Al}, \mathrm{KH}$ and $\mathrm{YO}$ participated in the design and coordination of the microflora reconstitution experiments. MaN, SI, and SM participated in the design of statistical and bioinformatics analyses. KW conceived the study and participated in its design and coordination. All authors read and approved the final manuscript.

Received: 16 April 2012 Accepted: 23 July 2012

Published: 23 July 2012

\section{References}

1. Strachan DP: Hay fever, hygiene, and household size. BMJ 1989, 299: 1259-1260.

2. Romagnani S: The increased prevalence of allergy and the hygiene hypothesis: missing immune deviation, reduced immune suppression, or both? Immunology 2004, 112:352-363.

3. Bjorksten B: The hygiene hypothesis: do we still believe in it? Nestle Nutr Workshop Ser Pediatr Program 2009, 64:11-18. discussion 18-22, 251-257.

4. Noverr MC, Huffnagle GB: The 'microflora hypothesis' of allergic diseases. Clin Exp Allergy 2005, 35:1511-1520.

5. Kosiewicz MM, Zirnheld AL, Alard P: Gut microbiota, immunity, and disease: a complex relationship. Front Microbiol 2011, 2:180.

6. Gronlund MM, Arvilommi H, Kero P, Lehtonen OP, Isolauri E: Importance of intestinal colonisation in the maturation of humoral immunity in early infancy: a prospective follow up study of healthy infants aged 0-6 months. Arch Dis Child Fetal Neonatal Ed 2000, 83:F186-F192.

7. Menard O, Butel MJ, Gaboriau-Routhiau V, Waligora-Dupriet AJ: Gnotobiotic mouse immune response induced by Bifidobacterium sp. strains isolated from infants. Appl Environ Microbiol 2008, 74:660-666.

8. Vercelli D: Mechanisms of the hygiene hypothesis-molecular and otherwise. Curr Opin Immunol 2006, 18:733-737.

9. Demengeot J, Zelenay S, Moraes-Fontes MF, Caramalho I, Coutinho A: Regulatory T cells in microbial infection. Springer Semin Immunopathol 2006, 28:41-50.

10. Gerrard JW, Geddes CA, Reggin PL, Gerrard CD, Horne S: Serum IgE levels in white and metis communities in Saskatchewan. Ann Allergy 1976, 37:91-100.

11. de Lara C, Noble A: Dishing the dirt on asthma: What we can learn from poor hygiene. Biologics 2007, 1:139-150.

12. Resi D, Milandri M, Moro ML: Antibiotic prescriptions in children. J Antimicrob Chemother 2003, 52:282-286.

13. Flohr C, Pascoe D, Williams HC: Atopic dermatitis and the 'hygiene hypothesis': too clean to be true? Br J Dermatol 2005, 152:202-216. 
14. Flohr C, Yeo L: Atopic dermatitis and the hygiene hypothesis revisited Curr Probl Dermatol 2011, 41:1-34

15. Tlaskalova-Hogenova H, Stepankova R, Kozakova H, Hudcovic T, Vannucci L, Tuckova L, Rossmann P, Hrncir T, Kverka M, Zakostelska Z, et al: The role of gut microbiota (commensal bacteria) and the mucosal barrier in the pathogenesis of inflammatory and autoimmune diseases and cancer: contribution of germ-free and gnotobiotic animal models of human diseases. Cell Mol Immunol 2011, 8:110-120.

16. Oyama N, Sudo N, Sogawa $H$, Kubo C: Antibiotic use during infancy promotes a shift in the $T(H) 1 / T(H) 2$ balance toward $T(H) 2$-dominant immunity in mice. J Allergy Clin Immunol 2001, 107:153-159.

17. Sudo N, Sawamura S, Tanaka K, Aiba Y, Kubo C, Koga Y: The requirement of intestinal bacterial flora for the development of an lgE production system fully susceptible to oral tolerance induction. J Immunol 1997 159:1739-1745.

18. Like AA, Rossini AA, Guberski DL, Appel MC, Williams RM: Spontaneous diabetes mellitus: reversal and prevention in the BB/W rat with antiserum to rat lymphocytes. Science 1979, 206:1421-1423.

19. Rossini AA, Williams RM, Mordes JP, Appel MC, Like AA: Spontaneous diabetes in the gnotobiotic BB/W rat. Diabetes 1979, 28:1031-1032.

20. Kohashi O, Kuwata J, Umehara K, Uemura F, Takahashi T, Ozawa A Susceptibility to adjuvant-induced arthritis among germfree, specific-pathogen-free, and conventional rats. Infect Immun 1979, 26:791-794.

21. Kohashi O, Kohashi Y, Takahashi T, Ozawa A, Shigematsu N: Reverse effect of gram-positive bacteria vs. gram-negative bacteria on adjuvant-induced arthritis in germfree rats. Microbiol Immunol 1985, 29:487-497.

22. Duchmann R, Kaiser I, Hermann E, Mayet W, Ewe K, Buschenfelde KH M: Tolerance exists towards resident intestinal flora but is broken in active inflammatory bowel disease (IBD). Clin Exp Immunol 1995, 102:448-455.

23. Musso G, Gambino R, Cassader M: Obesity, diabetes, and gut microbiota: the hygiene hypothesis expanded? Diabetes Care 2010, 33:2277-2284.

24. Okada H, Kuhn C, Feillet H, Bach JF: The 'hygiene hypothesis' for autoimmune and allergic diseases: an update. Clin Exp Immunol 2010, 160:1-9.

25. Subramanian A, Tamayo P, Mootha VK, Mukherjee S, Ebert BL, Gillette MA, Paulovich A, Pomeroy SL, Golub TR, Lander ES, Mesirov JP: Gene set enrichment analysis: a knowledge-based approach for interpreting genome-wide expression profiles. Proc Natl Acad Sci U S A 2005, 102:15545-15550.

26. Al-Shahrour F, Diaz-Uriarte R, Dopazo J: FatiGO: a web tool for finding significant associations of Gene Ontology terms with groups of genes. Bioinformatics 2004, 20:578-580.

27. Boorsma A, Foat BC, Vis D, Klis F, Bussemaker HJ: T-profiler: scoring the activity of predefined groups of genes using gene expression data. Nucleic Acids Res 2005, 33:W592-W595.

28. Khatri P, Draghici S: Ontological analysis of gene expression data: current tools, limitations, and open problems. Bioinformatics 2005, 21:3587-3595.

29. Kim SY, Volsky DJ: PAGE: parametric analysis of gene set enrichment. BMC Bioinforma 2005, 6:144

30. Yan X, Sun F: Testing gene set enrichment for subset of genes: Sub-GSE. BMC Bioinforma 2008, 9:362.

31. Dinu I, Potter JD, Mueller T, Liu Q, Adewale AJ, Jhangri GS, Einecke G, Famulski KS, Halloran P, Yasui Y: Improving gene set analysis of microarray data by SAM-GS. BMC Bioinforma 2007, 8:242

32. Lin R, Dai S, Irwin RD, Heinloth AN, Boorman GA, Li L: Gene set enrichment analysis for non-monotone association and multiple experimental categories. BMC Bioinforma 2008, 9:481

33. Abatangelo L, Maglietta R, Distaso A, D'Addabbo A, Creanza TM, Mukherjee S, Ancona N: Comparative study of gene set enrichment methods. BMC Bioinforma 2009, 10:275.

34. Gupta PK, Yoshida R, Imoto S, Yamaguchi R, Miyano S: Statistical absolute evaluation of gene ontology terms with gene expression data. LNBZ 2007, 4463:146-157.

35. Watanabe-Fukuda $Y$, Yamamoto M, Miura N, Fukutake $M$, Ishige A, Yamaguchi R, Nagasaki M, Saito A, Imoto S, Miyano S, et al: Orengedokuto and berberine improve indomethacin-induced small intestinal injury via adenosine. J Gastroenterol 2009, 44:380-389.

36. Munakata K, Yamamoto M, Anjiki N, Nishiyama M, Imamura S, lizuka S, Takashima K, Ishige A, Hioki K, Ohnishi Y, Watanabe K: Importance of the interferon-alpha system in murine large intestine indicated by microarray analysis of commensal bacteria-induced immunological changes. BMC Genomics 2008, 9:192.

37. Munakata K, Takashima K, Nishiyama M, Asano N, Mase A, Hioki K, Ohnishi Y, Yamamoto M, Watanabe K: Microarray analysis on germfree mice elucidates the primary target of a traditional Japanese medicine juzentaihoto: Acceleration of IFN-a response via affecting the ISGF3-IRF7 signaling cascade. BMC Genomics 2012, 130:30.

38. Bjorkholm B, Bok CM, Lundin A, Rafter J, Hibberd ML, Pettersson S: Intestinal microbiota regulate xenobiotic metabolism in the liver. PLOS One 2009, 4:e6958.

39. Beutler BA: TLRs and innate immunity. Blood 2009, 113:1399-1407.

40. Round JL, Lee SM, Li J, Tran G, Jabri B, Chatila TA, Mazmanian SK: The Tolllike receptor 2 pathway establishes colonization by a commensal of the human microbiota. Science 2011, 332:974-977.

41. Zeuthen LH, Fink LN, Metzdorff SB, Kristensen MB, Licht TR, Nellemann C, Frokiaer $\mathrm{H}$ : Lactobacillus acidophilus induces a slow but more sustained chemokine and cytokine response in naive foetal enterocytes compared to commensal Escherichia coli. BMC Immunol 2010, 11:2.

42. Lotz M, Gutle D, Walther S, Menard S, Bogdan C, Hornef MW: Postnatal acquisition of endotoxin tolerance in intestinal epithelial cells. J Exp Med 2006, 203:973-984

43. Schumann A, Nutten S, Donnicola D, Comelli EM, Mansourian R, Cherbut C, Corthesy-Theulaz I, Garcia-Rodenas C: Neonatal antibiotic treatment alters gastrointestinal tract developmental gene expression and intestinal barrier transcriptome. Physio/ Genomics 2005, 23:235-245.

44. Rhee SJ, Walker WA, Cherayil BJ: Developmentally regulated intestinal expression of IFN-gamma and its target genes and the age-specific response to enteric Salmonella infection. J Immunol 2005, 175:1127-1136.

45. Hooper LV, Wong MH, Thelin A, Hansson L, Falk PG, Gordon Jl: Molecular analysis of commensal host-microbial relationships in the intestine. Science 2001, 291:881-884

46. Chowdhury SR, King DE, Willing BP, Band MR, Beever JE, Lane AB, Loor JJ, Marini JC, Rund LA, Schook LB, et al: Transcriptome profiling of the small intestinal epithelium in germfree versus conventional piglets. $B M C$ Genomics 2007, 8:215.

47. Ashburner M, Ball CA, Blake JA, Botstein D, Butler H, Cherry JM, Davis AP, Dolinski K, Dwight SS, Eppig JT, et al: Gene ontology: tool for the unification of biology. The Gene Ontology Consortium. Nat Genet 2000, 25:25-29.

48. Schacherer F, Choi C, Gotze U, Krull M, Pistor S, Wingender E: The TRANSPATH signal transduction database: a knowledge base on signal transduction networks. Bioinformatics 2001, 17:1053-1057.

\section{doi:10.1186/1471-2164-13-335}

Cite this article as: Yamamoto et al:: A microarray analysis of gnotobiotic mice indicating that microbial exposure during the neonatal period plays an essential role in immune system development. BMC Genomics 2012 13:335.

\section{Submit your next manuscript to BioMed Central and take full advantage of:}

- Convenient online submission

- Thorough peer review

- No space constraints or color figure charges

- Immediate publication on acceptance

- Inclusion in PubMed, CAS, Scopus and Google Scholar

- Research which is freely available for redistribution 